\title{
Peertechz
}

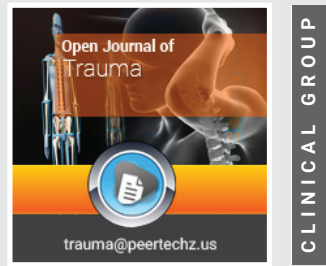

Research Article

\section{Traumas as social interactions}

\author{
Sam Vaknin* \\ Visiting Professor of Psychology, Southern Federal University, Rostov-on-Don, Russia
}

Received: 19 April, 2021

Accepted: 05 May, 2021

Published: 06 May, 2021

*Corresponding author: Sam Vaknin, PhD, Visiting Professor of Psychology, Southern Federal University, Rostov-on-Don, Russia, Tel: +38978319143, +79884640967; E-mail: samvaknin@gmail.com

https://www.peertechzpublications.com

Check for updates

\section{Abstract}

We react to serious mishaps, life altering setbacks, disasters, abuse, and death by going through the phases of grieving. Traumas are the complex outcomes of psychodynamic and biochemical processes. But the particulars of traumas depend heavily on the interaction between the victim and his social milieu.

It would seem that while the victim progresses from denial to helplessness, rage, depression and thence to acceptance of the traumatizing events - society demonstrates a diametrically opposed progression. This incompatibility, this mismatch of psychological phases is what leads to the formation and crystallization of trauma.

\section{Paper}

We react to serious mishaps, life altering setbacks, disasters, abuse, and death by going through the phases of grieving. Traumas are the complex outcomes of psychodynamic and biochemical processes. But the particulars of traumas depend heavily on the interaction between the victim and his social milieu.

It would seem that while the victim progresses from denial to helplessness, rage, depression and thence to acceptance of the traumatizing events - society demonstrates a diametrically opposed progression. This incompatibility, this mismatch of psychological phases is what leads to the formation and crystallization of trauma.

\section{Phase I}

The mismatch between the victim's reactive patterns and emotional needs and society's matter-of-fact attitude hinders growth and healing. The victim requires society's help in avoiding a head-on confrontation with a reality he cannot digest. Instead, society serves as a constant and mentally destabilizing reminder of the root of the victim's unbearable agony (the Job syndrome).

\section{Phase II}

Thus, when the victim is most in need, terrified by his helplessness and adrift - society is immersed in depression and unable to provide a holding and supporting environment. Growth and healing is again retarded by social interaction. The victim's innate sense of annulment is enhanced by the selfaddressed anger (=depression) of those around him.

\section{Phase III}

Both the victim and society react with RAGE to their predicaments. In an effort to narcissistically reassert himself, the victim develops a grandiose sense of anger directed at paranoidally selected, unreal, diffuse, and abstract targets (=frustration sources). By expressing aggression, the victim re-acquires mastery of the world and of himself.

Members of society use rage to re-direct the root cause of their depression (which is, as we said, self directed anger) and to channel it safely. To ensure that this expressed aggression alleviates their depression - real targets must are selected and real punishments meted out. In this respect, "social rage" differs from the victim's. The former is intended to sublimate aggression and channel it in a socially acceptable manner - the latter to reassert narcissistic self-love as an antidote to an alldevouring sense of helplessness.

In other words, society, by itself being in a state of rage, positively enforces the narcissistic rage reactions of the grieving victim. This, in the long run, is counter-productive, inhibits personal growth, and prevents healing. It also erodes the reality test of the victim and encourages self-delusions, paranoidal ideation, and ideas of reference. 


\section{Phase IV}

Again, the members of society are unable to help the victim to emerge from a self-destructive phase. His depression is enhanced by their apparent helplessness. Their introversion and inefficacy induce in the victim a feeling of nightmarish isolation and alienation. Healing and growth are once again retarded or even inhibited.

\section{Phase V}

This final mismatch between the victim's emotional needs and society's reactions is less damaging to the victim. He is now more resilient, stronger, more flexible, and more willing to forgive and forget. Society's denial is really a denial of the victim. But, having ridden himself of more primitive narcissistic defences - the victim can do without society's acceptance, approval, or look. Having endured the purgatory of grieving, he has now re-acquired his self, independent of society's acknowledgement.

\section{Sundry observations on trauma and post-traumatic conditions}

Trauma imprints everything and everyone involved or present in the stressful event, however tangentially. Places, people, smells, sounds, circumstances, objects, dates, and categories of the above, all get "stamped" with the traumatic experience.

Trauma imprinting is at the core of PTSD (Post-traumatic Stress Disorder), CPTSD (Complex PTSD), and triggering. Triggers are places, people, smells, sounds, circumstances, dates, or objects that are reminiscent of the same classes of stressors involved in the original trauma and evoke them.

Many exposure and retraumatization therapies (including, most recently, the treatment modality that I developed, Cold Therapy) make use of trauma imprinting to generate new, less stressful and less panic- or anxiety-inducing associations between extant triggers and thus to induce integration of the haywire emotions involved in the primary situation.

Major traumas can lead to either of two opposing outcomes: regression into infantile behaviors and defenses - or a spurt of personal growth and maturation. It all depends on how the trauma is processed.

Faced with devastatingly hurtful, overwhelming, and dysregulated emotions, personalities with a low level of organization react to trauma with decompensation, reckless acting out, and even psychotic microepisodes. Major depression and suicidal ideation are common.

In an attempt to restore a sense of safety, the individual regresses to an earlier - familiar and predictable - phase of life and evokes parental imagoes and introjects to protect, comfort, soothe, and take over responsibilities.

In a way, the trauma victim parents herself by splitting her mind into a benevolent, forgiving, unconditionally loving inner object (mother or father) and a wayward, defiant, independent, and rebellious child or teen who is largely oblivious to the consequences of her actions.

More balanced, emotionally regulated, and mature persons reframe the trauma by accommodating it in a rational, evidence-based (not fictitious or counterfactual) narrative. They modify their theories about the world and the way it operates. They set new boundaries and generate new values, beliefs, and rules of conduct (new schemas). They process their emotions fully and are thereby rendered more self-efficacious. In other words: they grow up, having leveraged their painful losses as an engine of positive development geared towards the attainment of favorable ling-term. results.

Abuse and attachment, trauma and bonding form parabolic relationships: up to the vertex (the low point of the parabola), one member of the pair (abuse, trauma) sustains and enhances the other (attachment, bonding). Beyond that point, the former weakens and undermines the latter.

The exact location of the vertex depends on individual experience, personal history, personality, cultural and social mores, peer input, and expectations.

\section{To simplify}

Up to a point, people - men and women - are attracted to abusers. When the maltreatment reaches the traumatic vertex, the emotional reaction flips and the hitherto victims are repelled by the gratuitous cruelty and are, therefore, ejected and catapulted out of the dyad, couple, or bond.

This means that good guys and decent women don't stand a chance in the sexual and relationship marketplace. They always amount to distant and unattractive second or rebound choices.

Nice guys and solid, stable gals are there to pick up the pieces, relegated to the unglamorous role of the sanitation workers of lopsided romance.

They are rarely anything more than pedestrian providers and co-parents or, if they luck out, intimate companions in between their spouses's extramarital affairs with other, more abusive and, therefore, more thrilling and appealing others.

Cold feet: the remorse that accompanies a - usually major - decision (like getting married or acquiring a home). It often leads to passive-aggressive, reckless, immoral, or destructive behaviors intended to undermine further action and reverse course.

The recipient of such mistreatment is traumatized: he feels rejected or abandoned or betrayed or cruelly and unjustly abused or damaged. Trust is shattered.

But cold feet have little to do with the target: the jilted fiancee or the dumped lover or the defaulted seller. Cold feet represent complex inner dynamics of avoidance, repetition compulsion, prior traumas, low self-esteem, a labile sense of self-worth and inadequacy, fear of the unknown, and emotional dysregulation (being overwhelmed)[1-18]. 
However, if you keep attracting into your life people who get cold feet, there could be a problem with your selection criteria - or with you. It behoves you to look into why you keep choosing the wrong folks - or what in you gives them cold feet.

"Triggering cascade" is when a seemingly minor trigger results in vastly disproportional trauma.

Painful memories, replete with the attendant negative emotions, are walled behind mental barriers: combinations of dams and firewalls [18-26].

Sometimes even an innocuous mishap or a merely unpleasant event rupture these defenses and decades of hurt are released in an avalanche that, at times, can be life threatening.

Narcissists and psychopaths are dreamwreckers: they are particularly adept at provoking triggering cascades by aggressively and contemptuously frustrating both individual and social expectations, cherished and life-sustaining hopes, deeply held beliefs, and ingrained fantasies and values.

Their lack of empathy, innate, goal focused cruelty and ruthlessness, absent impulse control, and mind boggling recklessness create a whiplash of shock and disorientation coupled with agony and a pervasive feeling of being existentially negated. Intolerable angst is the inevitable outcome.

\section{References}

1. Stormberg D, Roningstam E, Gunderson J, Tohen M (1998) Pathological Narcissism in Bipolar Disorder Patients. Journal of Personality Disorders 12 : 179-185. Link: https://bit.ly/2RxPlkr

2. Roningstam E (1996) Pathological Narcissism and Narcissistic Personality Disorder in Axis I Disorders. Harvard Review of Psychiatry 3: 326-340. Link: https://bit.ly/3eoOKuk

3. Alford, Fred C (1998) Narcissism: Socrates, the Frankfurt School and Psychoanalytic Theory - New Haven and London, Yale University Press. Link: https://bit.ly/3tkKSyR

4. Fairbairn WRD (1954) An Object Relations Theory of the Personality . Link: https://bit.ly/3tIXLZx

5. Freud S (1905) Three Essays on the Theory of Sexuality . Standard Edition of the Complete Psychological Works of Sigmund Freud 7. Link: https://bit.ly/3b504rO

6. Freud S (1991) On Narcissism.14:73-107. Link: https://bit.ly/33jmDGP

7. Golomb E (1995) Trapped in the Mirror : Adult Children of Narcissists in Their Struggle for Self - Quill.

8. Greenberg JR, Mitchell SA (1983) Object Relations in Psychoanalytic Theory Link: https://bit.ly/2PTz5tH
9. Grunberger B (1979) Narcissism: Psychoanalytic Essays . New York, International Universities Press. Link: https://bit.ly/3en3lky

10. Guntrip H (1961) Personality Structure and Human Interaction. New York, International Universities Press. Link: https://bit.ly/3utvhhS

11. Horowitz MJ (1975) Sliding Meanings: A defense against threat in narcissistic personalities. Int J Psychoanal Psychother 4: 167-180. Link: https://bit.ly/3erY4xX

12. Jacobson E (1964) The Self and the Object World. New York, International Universities Press. Link: https://bit.ly/3vLAoKs

13. Kernberg O (1975) Borderline Conditions and Pathological Narcissism. New York, Jason Aronson. Link: https://bit.ly/3enNAPX

14. Trust MK (1975) The Writings of Melanie Klein - Ed. Roger Money-Kyrle - 4 vols New York, Free Press.1964-75.

15. Kohut $H$ (1971) The Analysis of the Self - New York, International Universities Press. Link: https://bit.ly/3tqGQ86

16. Lasch C (1979) The Culture of Narcissism. New York, Warner Books. Link: https://bit.ly/3toflqz

17. Alexander $L$ (1997) Narcissism : Denial of the True Self - Touchstone Books Link: https://bit.ly/3unVEpj

18. Millon T, Davis RD (1995) Disorders of Personality: DSM IV and Beyond ,2nd ed. John Wiley and Sons. Link: https://bit.ly/3xNFk3j

19. Millon T (2000) Personality Disorders in Modern Life - New York: John Wiley and Sons. 188: 558. Link: https://bit.ly/3twrCyJ

20. Ronningstam E (1998) Disorders of Narcissism: Diagnostic, Clinical, and Empirical Implications . American Psychiatric Press. Link: https://bit.ly/3nTle1P

21. Ronningstam E (1996) Pathological Narcissism and Narcissistic Personality Disorder in Axis I Disorders. Harv Rev Psychiatry 3: 326-340. Link: https://bit.ly/3eXG0ur

22. Rothstein A (1984) The Narcissistic Pursuit of Reflection .International Universities Press.

23. Lester S (1974) Narcissistic Personality Disorders - A Clinical Discussion. Am Psychoanal Assoc 22: 292-306. Link: https://bit.ly/33gJldj

24. Daniel S (1985) The Interpersonal World of the Infant. A View from Psychoanalysis and Developmental Psychology. Link: https://bit.ly/3b3FgCO

25. David S, Roningstam E, Gunderson J, Tohen M (1998) Pathological Narcissism in Bipolar Disorder Patients. Journal of Personality Disorders 12: 179-185. Link: https://bit.ly/3xP5anv

26. Vaknin S (2015) Malignant Self Love - Narcissism Revisited, 10th revised impression - Skopje and Prague. Narcissus Publications. Link: https://bit.ly/3uq6hbp

27. Zweig P (1968) The Heresy of Self-Love: A Study of Subversive Individualism.

Copyright: () 2021 Vaknin S. This is an open-access article distributed under the terms of the Creative Commons Attribution License, which permits unrestricted use, distribution, and reproduction in any medium, provided the original author and source are credited. 